\title{
Cortical Auditory Event Related Potentials (P300) for Frequency Changing Dynamic Tones
}

\author{
Mohan Kumar Kalaiah ${ }^{1}$ and Usha Shastri ${ }^{2}$ \\ 1Department of Audiology and Speech Language Pathology, Kasturba Medical College (Manipal University), Mangalore, Karnataka, \\ ${ }^{2}$ NITTE Institute of Speech and Hearing, Mangalore, Karnataka, India
}

\author{
Received October 25, 2015 \\ Revised December 11, 2015 \\ Accepted January 29, 2016
}

Background and Objectives: P300 has been studied with a variety of stimuli. However, the nature of P300 has not been investigated for deviant stimuli which change its characteristics from standard stimuli after a period of time from onset. Subjects and Methods: Nine young adults with normal hearing participated in the study. The P300 was elicited using an oddball paradigm, the probability of standard and deviant stimuli was $80 \%$ and $20 \%$ respectively. Six stimuli were used to elicit P300, it included two pure-tones $(1,000 \mathrm{~Hz}$ and 2,000 Hz) and four tone-complexes (tones with frequency changes). Among these stimuli, 1,000 $\mathrm{Hz}$ tone served as standard while others served as deviant stimuli. The P300 was recorded in five separate blocks, with one of the deviant stimuli as target in each block. Electroencephalographic was recorded from electrode sites Fz, Cz, C3, C4, and Pz. Latency and amplitude of components of the cortical auditory evoked potentials were measured at Cz. Results: Waveforms obtained in the present study shows that, all the deviant stimuli elicited obligatory P1-N1-P2 for stimulus onset. 2,000 Hz deviant tone elicited P300 at a latency of 300 ms. While, tone-complexes elicited acoustic change complex (ACC) for frequency changes and finally elicited P300 at a latency of 600 ms. In addition, the results showed shorter latency and larger amplitude ACC and P300 for rising tone-complexes compared to falling tone-complexes. Conclusions: Tone-complexes elicited distinct waveforms compared to 2,000 Hz deviant tone. Rising tone-complexes which had an increase in frequency elicited shorter latency and larger amplitude responses, which could be attributed to perceptual bias for frequency changes.

J Audiol Otol 2016;20(1):22-30
KEY WORDS: P300 · Frequency changing tones · Acoustic change complex Cortical auditory evoked potentials · Doppler shift.

\section{Introduction}

P300 is a vertex positive event-related potential (ERP), occurring around $300 \mathrm{~ms}$ post-stimulus onset. It is elicited when listener detects a rare and unpredictable target stimulus in a train of standard stimuli, i.e., oddball paradigm [1]. Perceptual detection of difference between standard and target stimuli elicits P300. P300 has been recorded in response to various stimulus modalities; such as auditory [1], visual [2],

This is an Open Access article distributed under the terms of the Creative Commons Attribution Non-Commercial License (http://creativecommons org/licenses/by-nc/3.0/) which permits unrestricted non-commercial use, distribution, and reproduction in any medium, provided the original work is properly cited. and somatosensory stimuli [3]. In auditory modality, P300 has been recorded in response to a wide variety of auditory stimuli, which includes speech stimuli such as vowels [4], syllables [5], and words [6] as well as non-speech stimuli, such as clicks [7] and tone-bursts [8].

Tone-bursts are the most commonly used non-speech stimuli to evoke P300 [8-11]. When tone-bursts are used to elicit P300, the deviant stimuli differ either in its frequency $[2,9,10]$, intensity $[10,11]$ or duration $[10]$ with reference to the standard stimuli. Squires, et al. [8] recorded P300 for frequency contrast using $1,000 \mathrm{~Hz}$ and $1,500 \mathrm{~Hz}$ tone-bursts alternatively as standard and deviant stimuli. Similarly, Fein and Turetsky [9] evoked P300 using 1,000 $\mathrm{Hz}$ tone as standard and 2,000 $\mathrm{Hz}$ tone as deviant stimuli, and Ji, et al. [2] with 
tones of $600 \mathrm{~Hz}$ and $1,500 \mathrm{~Hz}$ as standard and deviant respectively. Results of the above studies showed that P300 was observed between 300 and $350 \mathrm{~ms}$ post stimulus onset. It is to be noted here that the above mentioned studies have used deviant stimuli which differ from the standard stimuli at their onset.

In contrast to studies which elicited P300 using nonspeech stimuli, investigators have used speech stimuli as standard and deviant stimuli, which differ from each other in the middle of its course [5]. Henkin, et al. [5] elicited P300 using non-meaningful consonant vowel consonant (CVC) stimuli which differ in their final position, either in terms of place of articulation or manner of articulation or both place and manner of articulation. The mean latency of P300 for these stimuli ranged between $642.6 \mathrm{~ms}$ and $624.9 \mathrm{~ms}$. When compared to non-speech stimuli, P300 latency reported in the above investigation is extremely prolonged. The prolonged latency has been attributed to 1) less synchronous neural response with increase in task difficulty, 2) longer duration of the stimuli, and 3 ) the relative positioning of the acoustic cues in the linguistic stimuli (difference between standard and deviant stimuli was in the final position of the CVC stimuli) [5].

To the best of our knowledge, there are no studies that have used non-speech deviant stimuli which differ from the standard in the middle of its course. Hence, it is interesting to know the characteristics of P300 elicited using deviant stimuli which differ from standard in the middle of its course. It is logical to expect delayed latency for P300, when the deviant stimulus differs from the standard stimulus after the onset, somewhere in the middle of its course. However, the precise nature of the $\mathrm{P} 300$ elicited in such a condition has not be described previously. In order to achieve the above aim, frequency changing tones were used to elicit P300 in the present study. Frequency and intensity changes in an ongoing sound, over a period of time, serves as a major cues for perception of auditory motion. Further, the human auditory system shows a perceptual bias towards the tones which increase in frequency or intensity, which indicates an approaching sound [12]. This bias for sounds with rising frequency and intensity has been suggested to help the observer to prepare for contact with a sound source, or an increased margin of safety on its approach [12]. However, the effect of such perceptual bias on the P300 is not known. By eliciting P300 for frequency changing tones, we can also understand the effect of perceptual bias for frequency changes on P300.

To investigate the nature of P300 for a dynamic deviant stimuli which changes from the standard in the middle of its course, both speech or non-speech stimuli can be used. When speech stimulus is used, the listener may depend on the linguistic knowledge while making a decision rather than making a decision based on purely acoustic cues. As the present study did not aim to address the linguistic processing of the stimuli, non-speech stimuli was used to record P300, where the decision made is purely based on acoustic cues. Specifically, the present study was carried out to investigate the difference in P300 that may be observed when elicited using dynamic non-speech stimuli which changes its frequency in the middle of its course as compared to the conventional stimuli which are static or differ from the standard stimuli at the onset of the stimuli. As mentioned above, we aimed to investigate whether perceptual bias is present in the auditory system for different changes in frequency of the deviant stimuli. To achieve this goal, P300 was elicited using five different combinations of deviant-standard stimuli and were compared across the deviant stimuli. Among these, one deviant stimulus differed from the standard at the onset (i.e., static) while remaining four deviant stimuli differed from standard in the middle (i.e., dynamic).

\section{Subjects and Methods}

\section{Participants}

Nine individuals ( 2 males and 7 females) aged between 17 to 26 years (mean $=20.3$ years) participated in the study. All the participants had normal hearing in both ears with puretone thresholds $\leq 15 \mathrm{~dB} \mathrm{HL}$ at octave frequencies between $250 \mathrm{~Hz}$ to $8,000 \mathrm{~Hz}$, and speech identification score greater than $90 \%$ at $40 \mathrm{~dB}$ SL (ref: pure-tone threshold average at $500 \mathrm{~Hz}, 1,000 \mathrm{~Hz}$, and 2,000 Hz). Immittance evaluation was also performed and all participants had A-type tympanogram with acoustic reflex present at normal levels, thus ensuring normal middle ear functioning. Prior to data collection, the participants were informed about the study and informed consent was obtained. Ethical approval was obtained from institutional ethics committee of All India Institute of Speech and Hearing, Mysore to carry out the present study.

\section{Stimuli}

Six stimuli were used to elicit P300, which included puretone of $1,000 \mathrm{~Hz}$ and $2,000 \mathrm{~Hz}$, and four frequency changing tones (or tone-complex). Frequency changing tones were created by concatenating two equal amplitude pure-tones (e.g. $\mathrm{fl}=1,000 \mathrm{~Hz}$ followed by a $\mathrm{f} 2=3,000 \mathrm{~Hz}$, for rising 1 tone-complex) [13]. Frequency of initial pure-tone was always fixed at $1,000 \mathrm{~Hz}$ while the frequency of following pure-tone was varied. In order to have a smooth transition from f1 to f2 frequency and avoid large spectral splatter, a $30 \mathrm{~ms}$ linear 
Table 1. Description of the six stimuli used in the study

\begin{tabular}{lccc}
\hline \multicolumn{1}{c}{ Stimuli } & Standard/deviant & $\mathrm{F} 1(\mathrm{~Hz})$ & $\mathrm{F} 2(\mathrm{~Hz})$ \\
\hline $1,000 \mathrm{~Hz}$ tone & Standard & 1,000 & - \\
$2,000 \mathrm{~Hz}$ tone & Deviant & 2,000 & - \\
Rising 1 tone-complex & Deviant & 1,000 & 3,000 \\
Rising 2 tone-complex & Deviant & 1,000 & 2,000 \\
Falling 1 tone-complex & Deviant & 1,000 & 500 \\
Falling 2 tone-complex & Deviant & 1,000 & 750 \\
\hline
\end{tabular}

$\mathrm{Fl}$ : strating frequency, F2: ending frequency

chirp was introduced between two pure-tones. This transition from $\mathrm{f} 1$ to $\mathrm{f} 2$ occurred at $200 \mathrm{~ms}$ from the onset of the stimuli. Duration of all the stimuli was $400 \mathrm{~ms}$. All the stimuli were gated using raised cosine function with rise/fall time of $10 \mathrm{~ms}$. Description of these six stimuli are given in Table 1. All the stimuli were generated using MATLAB 7.9 (Mathworks Inc., Natick, MA, USA). Fig. 1 shows spectrogram of all the stimuli used to P300.

\section{P300 paradigm}

The P300 was elicited using a standard auditory oddball paradigm and the task was to discriminate a deviant tone or tone-complex from a standard tone. All the stimuli were presented monaurally to right ear of the participants, through a shielded transducer (Etymotic Type ER-3A; Etymotic Research, Chicago, IL, USA). The P300 was recorded in five blocks, in each block $1000 \mathrm{~Hz}$ tone served as standard stimulus and one of the five deviant stimuli served as deviant stimulus. The order of deviant stimuli used to elicit P300 in each block was randomized across the participants. Each block comprised presentation of 400 sweeps (or stimuli), among which $80 \%$ of the sweeps were standard and $20 \%$ were deviant. All the stimuli were presented at $80 \mathrm{~dB}$ SPL, and the inter-stimulus interval was $1.5 \mathrm{~s}$. When participants detect deviant stimuli, they were instructed to press a button on a response pad with the thumb of their preferred hand. A PC-based Neuro-Scan Stim² (Compumedics, Melbourne, Australia) was used for presentation of stimuli.

\section{Electroencephalographic (EEG) recordings}

During recording of P300, participants were fitted with a QuickCap $^{\mathrm{TM}}$ (Compumedics) and seated on a reclining chair in comfortable position. EEG was recorded from $\mathrm{Fz}, \mathrm{Cz}, \mathrm{C} 3$, $\mathrm{C} 4$, and Pz electrode sites of the 10-20 system [14], using a PC-based Neuro-Scan SynAmps ${ }^{2}$ data acquisition system (Compumedics). All electrodes were referenced to the right mastoid (A2) with ground on left mastoid (A1). Electrode impedance at each electrode was kept below $5 \mathrm{k} \Omega$. The ongoing EEG was band-pass filtered $(0.1-100 \mathrm{~Hz})$ and digitized at a rate of $1,000 \mathrm{~Hz}$ and stored to disk for off-line analysis. A
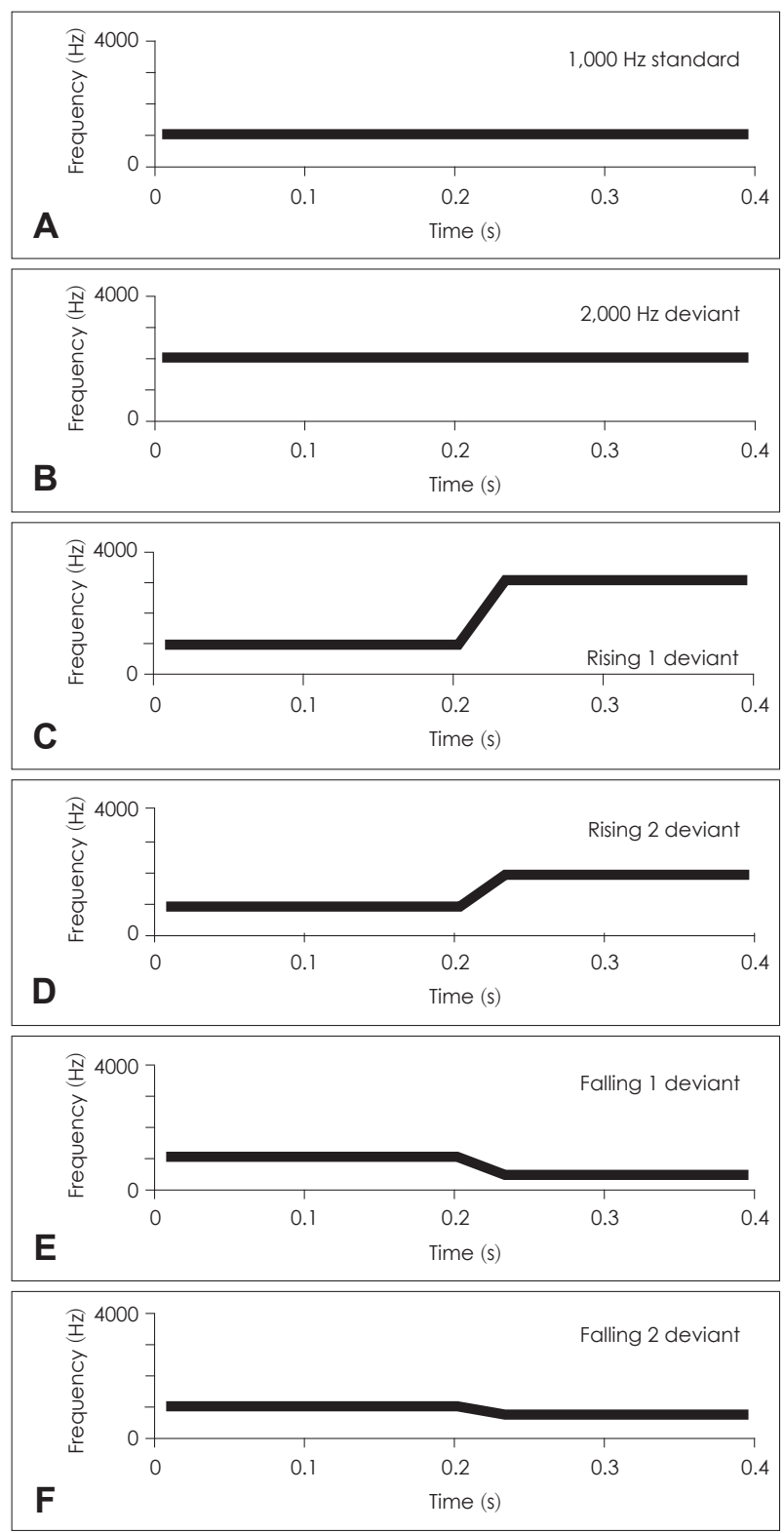

Fig. 1. Spectrogram of the stimuli used to elicit P300. First two panels from top (A, B) shows spectrogram of $1,000 \mathrm{~Hz}$ and 2,000 $\mathrm{Hz}$ pure-tone respectively. C-F show spectrogram of rising 1 , rising 2 , falling 1 , and falling 2 tone-complex respectively.

short break of 5-10 min was provided between the recordings as required by the participant. Continous EEG was segmented off-line for a total duration of $1400 \mathrm{~ms}$ with a prestimulus baseline of $100 \mathrm{~ms}$. The segmented data were digitally band-pass filtered between 0.1 and $30 \mathrm{~Hz}$ using zero-phase shift finate impulse response filter ( $12 \mathrm{~dB}$ /octave slope). Prior to averaging, segments that were judged to be noisy and/ or those with amplitude greater than $\pm 75 \mu \mathrm{V}$ were excluded from averaging. Averaging was carried out separately for standard and deviant stimuli. All off-line analysis was carried out using edit module of Scan (version 4.4) system software 
(Compumedics, Vienna, Australia). A minimum of 60 artifact-free samples (deviant stimuli) were accepted for each of the five standard-deviant combinations used to elicit P300. All the recordings were carried out in a sound-attenuating electrically-shielded room.

\section{Data analysis}

The waveforms obtained from all the participants were grand averaged for each electrode site, for standard and each deviant stimulus separately to identify various components or peaks of ERP. Peak latency and amplitude of the components of the ERP were measured at vertex $(\mathrm{Cz})$. Peak amplitude was measured relative to the pre-stimulus baseline and peak latency was measured from the stimulus onset. ShapiroWilk test was carried out to check whether data (latency and peak amplitude) are normally distributed, the result showed lack of normal distribution. Since the data was not normally distributed, Wilcoxon Signed Rank test was carried out to investigate if the mean latency and amplitudes are significantly different between standard and deviant stimuli. Friedman test was carried out to investigate if the mean latencies and amplitudes are significantly different across deviant tones. All statistical analysis were carried out using Statistical Package for Social Sciences software version 16 (SPSS Inc., Chicago, IL, USA).

\section{Results}

The grand averaged waveforms obtained from all the participants at vertex for 1,000 Hz standard, 2,000 Hz deviant, and falling 1 tone-complex deviant stimuli are shown in figure 2. In Fig. 2, it can be observed that both standard and deviant stimuli elicited obligatory P1-N1-P2 for the stimulus onset. In contrast, $2,000 \mathrm{~Hz}$ deviant stimuli evoked $\mathrm{P}_{300}$ following the obligatory response, while falling 1 tone-complex elicited multiple peaks. Multiple peaks elicited by falling 1 tone-complex included three positive peaks at 270, 450 and $600 \mathrm{~ms}$, labeled as $\mathrm{P}_{270}, \mathrm{P}_{450}$ and $\mathrm{P}_{600}$, and two negative peaks at 330 and $470 \mathrm{~ms}$, labeled as $\mathrm{N}_{330}$ and $\mathrm{N}_{470}$ respectively based on the polarity and latency of the peaks. The waveforms obtained for other frequency changing deviant stimuli was similar to that of falling 1 tone-complex. Further, in Fig. 2 it can also be noted that the latency and peak amplitude of P1, N1 and $\mathrm{P} 2$ are similar for $1,000 \mathrm{~Hz}$ tone and falling 1 tone-complex, while peak amplitude of all peaks showed greater negativity for $2,000 \mathrm{~Hz}$ tone.

\section{Obligatory P1-N1-P2 response}

Fig. 3 shows mean and standard deviation for latency (Fig. 3A) and peak amplitude (Fig. 3B) of P1, N1 and P2 at Cz for standard and deviant stimuli. Wilcoxon Signed Rank test was administered to determine if the latency and amplitude of P1, $\mathrm{N} 1$ and P2 are significantly different between standard and

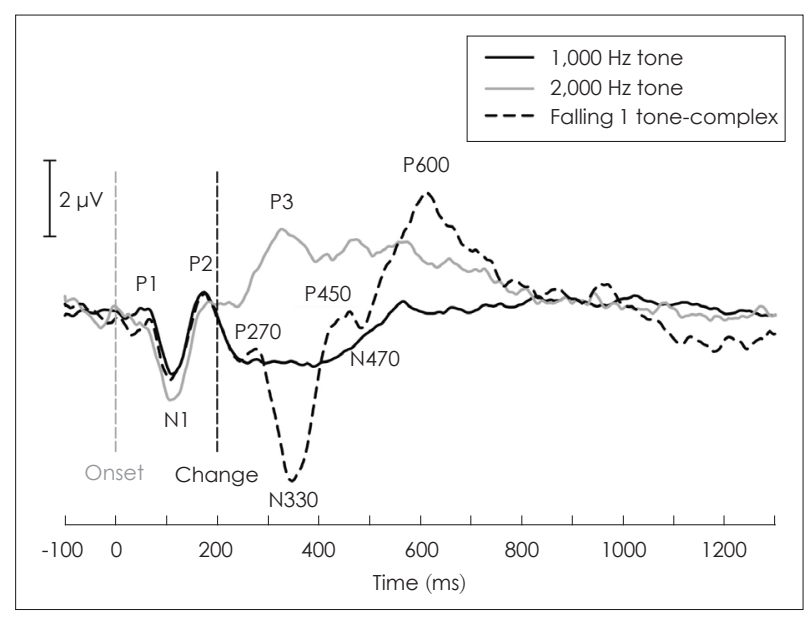

Fig. 2. Grand averaged waveforms of auditory evoked potentials recorded at $\mathrm{Cz}$ for $1,000 \mathrm{~Hz}$ standard tone (black solid line), 2,000 $\mathrm{Hz}$ deviant tone (light grey solid line) and falling 1 deviant tonecomplex (black dashed line). Vertical dashed lines at $0 \mathrm{~ms}$ (light grey) indicates stimulus onset and at $200 \mathrm{~ms}$ (black) indicates frequency change for tone-complexes.
Fig. 3. Mean and standard deviation for latency $(A)$ and peak amplitude (B) of peaks of obligatory P1-N1-P2 response for standard and deviant stimuli. R1, R2, F1, and F2 represents rising 1 , rising 2 , falling 1 , and falling 2 tone-complex respectively.

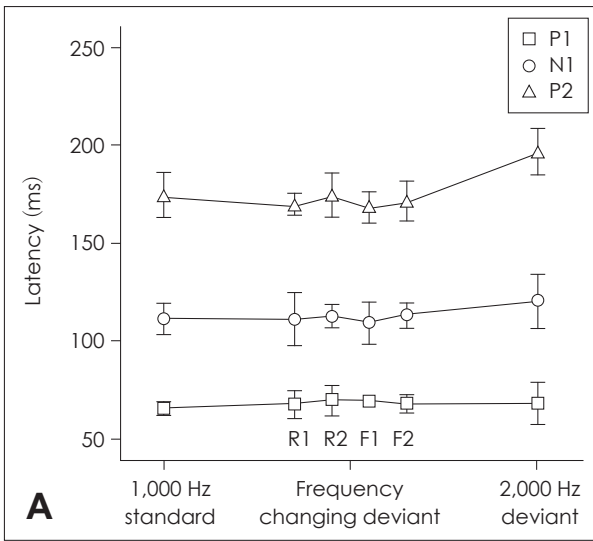


two deviant stimuli. It showed a significant prolongation for latency of P2 for $2000 \mathrm{~Hz}$ tone ( $\mathrm{Z}=-2.366, p<0.05)$, while the latency of other peaks were not significantly different $(p>0.05)$. Further, the peak amplitude of N1 evoked by 2000 $\mathrm{Hz}$ tone had significantly greater negativity $(\mathrm{Z}=-2.384, p<0.05)$ when compared to that of $1,000 \mathrm{~Hz}$ standard stimuli, while P1 and P2 amplitudes were not significantly different $(p>0.05)$ across the stimuli.

Fig. 4 shows grand averaged waveforms of obligatory P1N1-P2 response for various deviant stimuli. In the figure, it can be observed that $2000 \mathrm{~Hz}$ tone elicits greater negativity for all the peaks. Mean and standard deviation for latency (Fig. 3A) and amplitude (Fig. 3B) of P1, N1 and P2 for deviant stimuli are shown in Fig. 4. Friedman test showed a significant difference for P2 latency $\left[\chi^{2}(4)=12.993, p<0.05\right]$ and

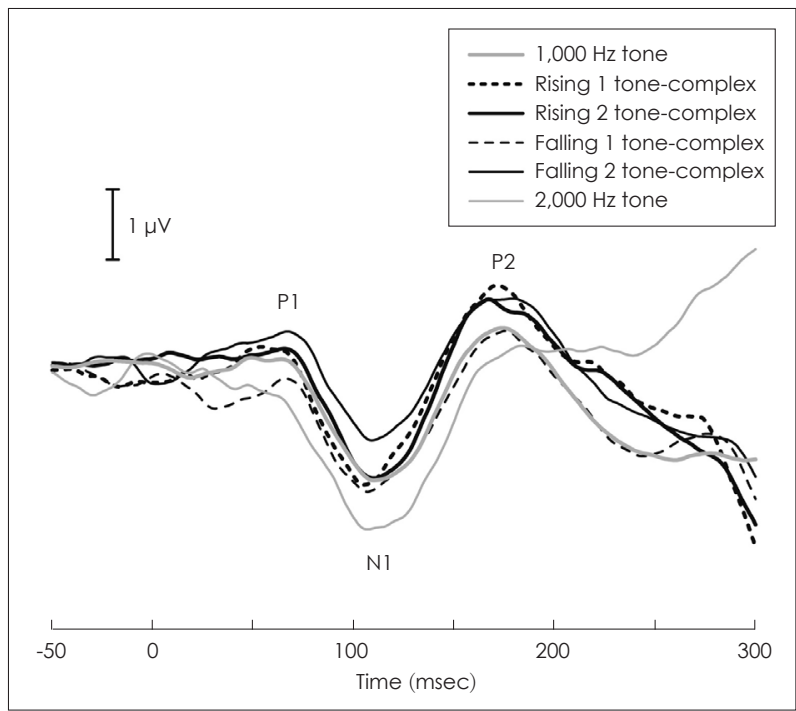

Fig. 4. Grand averaged waveforms of obligatory P1-N1-P2 response at $\mathrm{Cz}$ for various deviant stimuli. Light grey waveform represents response for $2,000 \mathrm{~Hz}$ tone. Dark grey waveform shows response for rising 1 tone-complex (dotted line) and rising 2 tonecomplex (solid line). Thin black lines represent response for falling 1 tone-complex (dashed line) and falling 2 tone-complex (solid line).
N1 peak amplitude $\left[\chi^{2}(4)=11.196, p<0.05\right]$ across the deviant stimuli. Pair-wise comparison between deviant stimuli using Wilcoxon Signed Rank Test revealed that latency of P2 was significantly longer $(p<0.05)$ and peak amplitude of N1 was significantly more negative $(p<0.05)$ for $2,000 \mathrm{~Hz}$ tone compared to all the frequency changing tone-complex.

\section{Cortical auditory ERPs for deviant stimuli}

From Fig. 2 it can be observed that 2,000 Hz deviant stimulus evoked an obligatory P1-N1-P2 response for stimulus onset and was followed by a broad positivity, P300, at a mean latency of $340 \mathrm{~ms}$. P300 was present in all the participants at latency ranging between $317 \mathrm{~ms}$ and $506 \mathrm{~ms}$ and amplitude ranging from $3.6 \mu \mathrm{V}$ to $10.2 \mu \mathrm{V}$ (mean $=5.9 \mu \mathrm{V}$ ). This finding in the present study is comparable to the findings reported in literature $[2,8,9]$. In contrast to $2,000 \mathrm{~Hz}$ tone, frequency changing tone-complex evoked multiple peaks labelled as $\mathrm{P}_{270}, \mathrm{~N}_{330}, \mathrm{P}_{450}, \mathrm{~N}_{470}$ and $\mathrm{P}_{600}$. Among these peaks, $\mathrm{N}_{330}, \mathrm{P}_{450}$

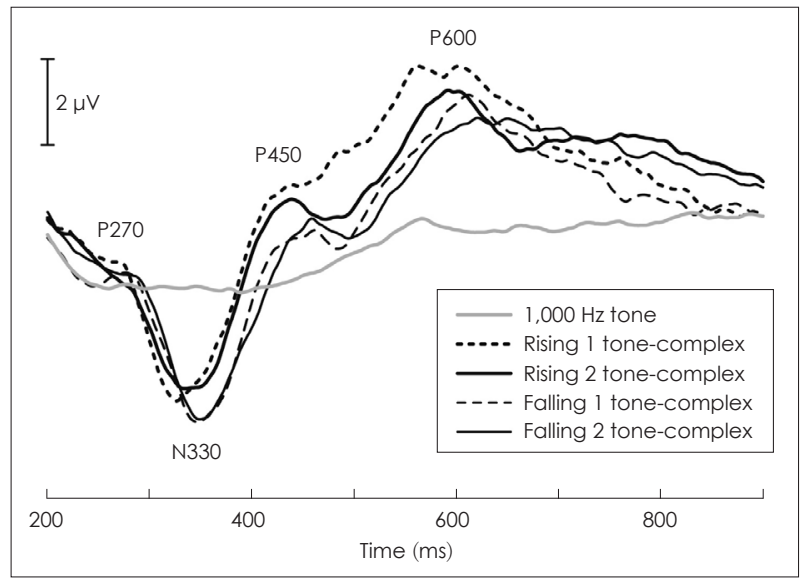

Fig. 5. Grand averaged waveforms of auditory evoked potentials, between 200 and $700 \mathrm{~ms}$, at $\mathrm{Cz}$ for various frequency changing tone-complexes. Dark grey lines represent response for rising 1 tone-complex (dotted line) and rising 2 tone-complex (solid line). Thin black lines represent response for falling 1 tone-complex (dashed line) and falling 2 tone-complex (solid line).

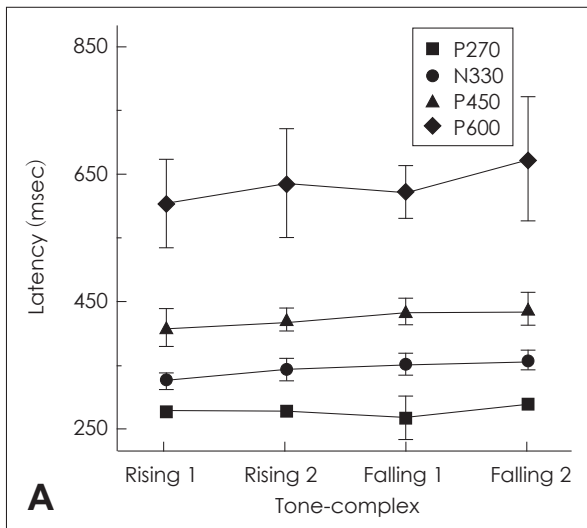

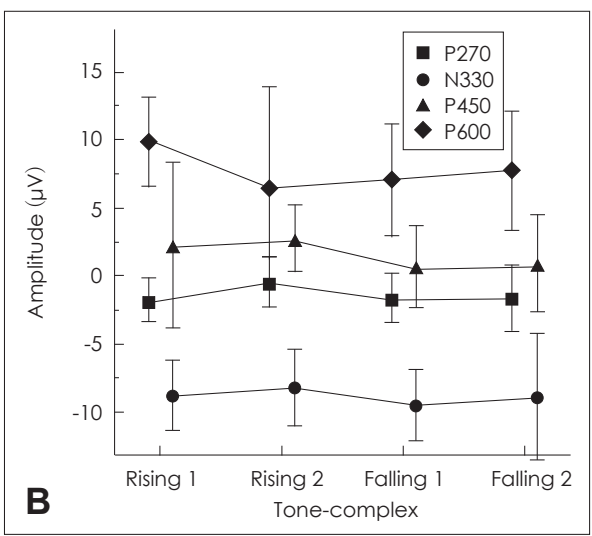

Fig. 6. Mean and standard deviation for latency $(A)$ and peak amplitude (B) of $\mathrm{P}_{270}, \mathrm{~N}_{330}, \mathrm{P}_{450}$, and $\mathrm{P}_{600}$ for various frequency changing tonecomplexes. 
and $\mathrm{P}_{600}$ was present in all the participants, while $\mathrm{P}_{270}$ and $\mathrm{N}_{470}$ could be identified in eight and six participants respectively. $\mathrm{P}_{270}$ was observed at latency between $269 \mathrm{~ms}$ and 286 $\mathrm{ms}, \mathrm{N}_{330}$ between $328 \mathrm{~ms}$ and $352 \mathrm{~ms}, \mathrm{P}_{450}$ between $409 \mathrm{~ms}$ and $440 \mathrm{~ms}$ and N470 between $470 \mathrm{~ms}$ and $501 \mathrm{~ms}$. These peaks were followed by a large positive peak, $\mathrm{P}_{600}$, at latency between $603 \mathrm{~ms}$ and $672 \mathrm{~ms}$.

The grand averaged waveforms obtained for all the frequency changing deviant tone-complex showing only $\mathrm{P}_{270}$, $\mathrm{N}_{330}, \mathrm{P}_{450}$, and $\mathrm{P}_{600}$ are shown in Fig. 5, and the mean latency and amplitude of these peaks are shown in Fig. 6. From Fig. 6 it is evident that the latency of $\mathrm{N}_{330}$ is shortest for rising 1 tonecomplex followed by rising 2 , falling 1 and falling 2 tone-complexes which had a frequency change of 2,000, 1,000, 500, and $250 \mathrm{~Hz}$ respectively. To investigate if the mean latencies and amplitudes of $\mathrm{P}_{270}, \mathrm{~N}_{330}, \mathrm{P}_{450}, \mathrm{~N}_{470}$, and $\mathrm{P}_{600}$ across frequency changing deviant tones are significantly different, the data was subjected to Friedman test. It showed significant differ-
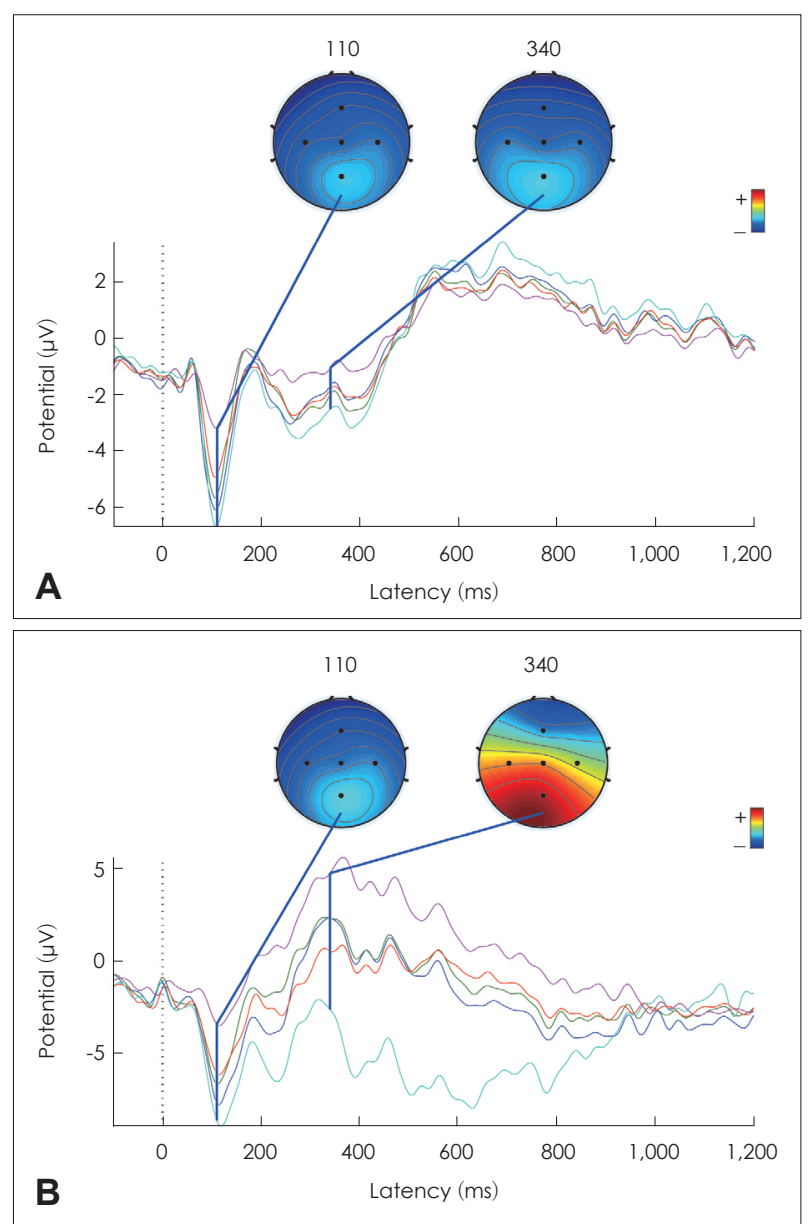

Fig. 7. Averaged waveforms of auditory evoked potentials at Fz, $\mathrm{Cz}, \mathrm{Pz}, \mathrm{C} 3$ and $\mathrm{C} 4$, and scalp maps showing topographic distribution of average potential at $110 \mathrm{~ms}$ and $340 \mathrm{~ms}$ which corresponds to N1 and P300 for 1,000 Hz standard tone (A) and 2,000 $\mathrm{Hz}$ deviant tone $(\mathrm{B})$. ence for latency of $\mathrm{N}_{330}\left[\chi^{2}(3)=9.667, p<0.05\right]$ and $\mathrm{P}_{450}$ $\left[\chi^{2}(3)=12.150, p<0.05\right]$, while latency of $\mathrm{P}_{270}\left[\chi^{2}(3)=7.800, p=\right.$ $0.05], \mathrm{N}_{470}\left[\chi^{2}(3)=1, p=0.801\right]$ and $\mathrm{P}_{600}\left[\chi^{2}(3)=5.427, p=\right.$ $0.143]$ was not significantly different across frequency changing tone-complex. Further, results showed no significant difference between peak amplitudes across the tone-complex $\left[\mathrm{P}_{270}: \chi^{2}(3)=3.105, p=0.376 ; \mathrm{N}_{330}: \chi^{2}(3)=1.112, p=0.774\right.$; $\mathrm{P}_{450}: \chi^{2}(3)=2.250, p=0.552 ; \mathrm{N}_{470}: \chi^{2}(3)=5.000, p=0.172 ; \mathrm{P}_{600}$ : $\chi^{2}(3)=3.400, p=0.334$ ]. Pair-wise comparison using Wilcoxon Signed Rank test revealed that the latency of $\mathrm{N}_{330}$ for rising 1 tone-complex was significantly shorter $(p<0.05)$ compared to other tone-complex. The latency of P450 of rising 1 tone-complex was significantly shorter $(p<0.05)$ than falling 2 tone-complex.

To understand the current distribution in the scalp for various components $\left(\mathrm{N}_{1}, \mathrm{P}_{300}, \mathrm{~N}_{330}\right.$, and $\left.\mathrm{P}_{600}\right)$ of auditory evoked potentials, scalp current density maps were obtained using EEGLAB [15]. The scalp maps were obtained at latency of about $110 \mathrm{~ms}$ post-stimulus onset, equivalent to the latency of obligatory N1, for both standard and deviant stimuli. In addition, the scalp maps were also obtained at about $340 \mathrm{~ms}$ post-stimulus onset for $2,000 \mathrm{~Hz}$ deviant stimuli, equivalent to latency of P300, and at latencies of about 350 and $610 \mathrm{~ms}$ for frequency changing tone-complex, equivalent to $\mathrm{N}_{330}$ and $\mathrm{P}_{600}$ respectivrly. These scalp current density maps are shown in Fig. 7, 8. In Fig. 7, it can be observed that the scalp map at N1 latency for both standard and deviant stimuli shows greater negativity in the frontal region of the scalp, and the negativity decreases towards posterior regions. Scalp map obtained at $340 \mathrm{~ms}$ for 2,000 Hz deviant tone, which corresponds to $\mathrm{P} 300$, shows greater positivity in the posterior region (bottom panel) which decreases towards frontal region. The scalp

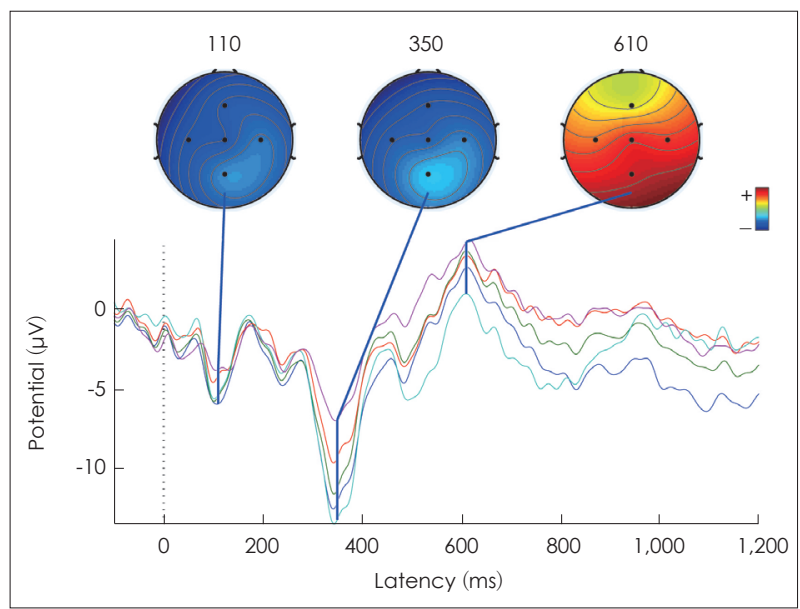

Fig. 8. Averaged waveforms of auditory evoked potentials at Fz, $\mathrm{Cz}, \mathrm{Pz}, \mathrm{C} 3$ and C4, and scalp maps showing topographic distribution of average potential at $110 \mathrm{~ms}, 350 \mathrm{~ms}$ and $610 \mathrm{~ms}$ which corresponds to N1, N330 and P600 for falling 1 tone-complex. 
maps of $\mathrm{N}_{330}$ and $\mathrm{P}_{600}$ of falling 1 tone-complex are shown in figure 8. It reveals that, the scalp map of $\mathrm{N}_{330}$ show large negativity in the frontal region of scalp and the negativity reduces in the posterior regions, similar to N1 of obligatory response. Scalp map for $\mathrm{P}_{600}$ shows greater positivity in the parietal region of the scalp and it decreases in the frontal regions, similar to P300.

\section{Discussion}

\section{Obligatory P1-N1-P2 response}

The finding of the present study showed that, P2 latency of obligatory response was significantly longer for $2,000 \mathrm{~Hz}$ tone compared to standard and frequency changing tone-complex. This could be because of complex interaction between the P2 of obligatory response and N2 (a discriminative negativity elicited for detection of rare deviant stimuli in oddball paradigm), for 2,000 Hz tone. Further, the amplitude of N1 for $2,000 \mathrm{~Hz}$ tone had significantly greater negativity compared to $1,000 \mathrm{~Hz}$ tone and tone-complexes. This finding may be attributed to stronger response of cortical neurons for rare deviant stimuli in a train of frequently presented standard stimuli $[16,17]$. But, amplitude of N1 was not significantly different between frequency changing tone-complex and 1,000 Hz standard tone, though frequency changing tone-complex was presented rarely. This finding may be explained based on similarity in the frequency characteristics of $1,000 \mathrm{~Hz}$ tone and tone-complexes at their onset. In Fig. 1 it can be observed that both $1,000 \mathrm{~Hz}$ standard and frequency changing tones begin with the same frequency, i.e. $1,000 \mathrm{~Hz}$, hence, the obligatory P1-N1-P2 evoked were similar for both stimuli even though the frequency changing deviants were delivered rarely.

\section{Cortical auditory ERPs for deviant stimuli}

Scalp map at N1 latency for both standard and deviant stimuli shows greater negativity in the frontal region of the scalp, characterized by the neural activity in the frontal scalp region. This finding is consistent with earlier investigations which shows that $\mathrm{N} 1$ is generated from the fronto-central region [18-20]. The scalp map obtained at $340 \mathrm{~ms}$ for $2,000 \mathrm{~Hz}$ deviant tone shows a greater positivity in the posterior region of the scalp, indicating greater activity in the parietal region. This finding is also in agreement with the findings reported in literature for $\mathrm{P}_{300}[2,21,22]$.

The scalp map of $\mathrm{N}_{330}$ of frequency changing tone-complex is similar to the scalp map of N1 of obligatory response. Based on the similarity between the scalp maps of N1 and $\mathrm{N} 330$ it may be expected that both $\mathrm{N} 1$ and $\mathrm{N}_{330}$ to be reflection of the same process in the brain. Therefore, it is possible that $\mathrm{P}_{270}, \mathrm{~N}_{330}$, and $\mathrm{P}_{450}$ is also an obligatory $\mathrm{P} 1-\mathrm{N} 1-\mathrm{P} 2$ elicited in response to frequency change in the tone-complex. In support to the above explanation, various studies have shown to elicit multiple P1-N1-P2 response for frequency change in an ongoing stimulus $[13,23,24]$, termed as acoustic change complex (ACC) [23]. Hence, the components $\mathrm{P}_{270}, \mathrm{~N}_{330}$, and $\mathrm{P}_{450}$ observed in the present study is nothing but ACC elicited for change in the frequency of tone-complex.

The scalp map of $\mathrm{P}_{600}$ of tone-complex showed greater positivity in the parietal region similar to the scalp map of P300 for $2000 \mathrm{~Hz}$ tone. This scalp topography is consistent with the cognitive processes in brain for detection of deviant stimuli. Hence, $\mathrm{P}_{600}$ may be assumed to be reflecting the same process that is involved in generation of $\mathrm{P} 300$ or the decision making. The latency of $\mathrm{P} 300$ reflects the time required for classification of the stimuli, which would be proportional to the time taken to detect and evaluate a target stimulus $[25,26]$. In the present study, frequency changing tone-complex differed from the standard tone at $200 \mathrm{~ms}$ after its onset. Hence, it can be expected that the participants took more time for detecting and evaluating the deviant stimuli, thus resulting in prolonged latency for $\mathrm{P}_{300}$. In addition, the latency of $\mathrm{P}_{300}$ has been reported to be dependent on the processing demand imposed by the stimulus, i.e., greater processing demand results in prolonged P300 [27,28]. The complex-tones used in the present study also might have introduced a processing delay as they are slightly more complex than the steady tone, which might have also contributed for the prolongation of $\mathrm{P}_{300}$. Thus, both the positioning of the acoustic change in the target stimulus in relation to standard stimulus, and the complexity of the target stimulus might have resulted in the prolonged latency of $\mathrm{P}_{300}$ for tone-complex.

\section{Comparison of latency and amplitude among deviant stimuli}

The latency of $\mathrm{N}_{330}$ and $\mathrm{P}_{600}$ was found to be shortest for rising 1 tone-complex followed by rising 2 , falling 1 , and falling 2 tone-complexes which had a frequency change of 2,000, 1,000, 500, and $250 \mathrm{~Hz}$ respectively. Similar result was observed for amplitude of $\mathrm{N}_{330}-\mathrm{P}_{450}$ peak to peak amplitude and $\mathrm{P}_{600}$ peak amplitude, i.e., largest amplitude was obtained for rising 1 tone-complex followed by rising 2, falling 1 and falling 2 tone-complexes. These findings shows that shorter latency and larger amplitude is obtained for largest change in frequency. In addition, from the result of the present study it can also be observed that the latency of $\mathrm{N}_{330}$ and $\mathrm{P}_{600}$ was shorter and amplitude of $\mathrm{N}_{330}-\mathrm{P}_{450}$ and $\mathrm{P}_{600}$ was largest for rising 1 and rising 2 tone-complexes, which increased their frequency, compared to falling 1 and falling 2 tone-complexes. 
The differences for latency and amplitude between rising and falling tone-complexes may be attributed to two reasons. First, increase and decrease in the frequency of rising and falling tone-complexes in the present study is similar to Doppler frequency shifts for an approaching and receding sounds in the natural environment. The Doppler frequency shifts provide important cues about the direction of sound movement [12], and a rise in frequency is perceived as more sailent by the listeners [29], which results in a bias towards a rise in sound frequency or approaching sounds. Thus, shorter latency and larger amplitude obtained in the present study for rising tonecomplexes could also be a consequence of perceptual bias in the auditory system for approaching sounds. This perceptual bias has been related to serve as a warning cue for looming auditory motion in natural environment, to identify the approaching source $[12,30,31]$. Second, in this study the magnitude of change in frequency for rising tone-complexes were larger than magnitude of change for falling tone-complexes. Hence, shorter latency for rising tone-complexes may also be a consequence of magnitude of frequency change. Further, earlier investigations have showed that a large change in frequency elicits shorter latency and larger amplitude ACC [32-35] and P300 [10]. Thus, shorter latency and larger amplitude for rising tones cannot be completely attributed to perceptual bias. Further, we have employed frequency change of different madnitudes for rising and falling tonecomplexes, this is one limitation in the present study. The effect of perceptual bias on the ACC and P300 can be better understood by replicating the study using frequency change of equal magnitudes for rising and falling tone-complexes.

In conclusion, characteristics of the cortical auditory evoked potentials in odd ball paradigm using non-speech deviant stimuli which differ from the standard in the middle of its course was investigated in the present study. Frequency changing deviant tones elicited ACC as well as P300. Furthermore, $\mathrm{N}_{330}$ (analogous to N1 of obligatory response) for rising tonecomplex had shorter latency than falling tone-complex. This finding might be indicating the perceptual bias of the auditory system towards the approaching sound than receding sounds.

\section{Conflicts of interest}

The authors have no financial conflicts of interest.

\section{REFERENCES}

1) Sutton S, Braren M, Zubin J, John ER. Evoked-potential correlates of stimulus uncertainty. Science 1965;150:1187-8.

2) Ji J, Porjesz B, Begleiter H, Chorlian D. P300: the similarities and differences in the scalp distribution of visual and auditory modality. Brain Topogr 1999;11:315-27.

3) Kida T, Nishihira Y, Hatta A, Wasaka T, Tazoe T, Sakajiri Y, et al.
Resource allocation and somatosensory P300 amplitude during dual task: effects of tracking speed and predictability of tracking direction. Clin Neurophysiol 2004;115:2616-28.

4) Beynon AJ, Snik AF, Stegeman DF, van den Broek P. Discrimination of speech sound contrasts determined with behavioral tests and event-related potentials in cochlear implant recipients. J Am Acad Audiol 2005;16:42-53.

5) Henkin Y, Kishon-Rabin L, Gadoth N, Pratt H. Auditory event-related potentials during phonetic and semantic processing in children. Audiol Neurootol 2002;7:228-39.

6) Weber-Fox C, Leonard LB, Wray AH, Tomblin JB. Electrophysiological correlates of rapid auditory and linguistic processing in adolescents with specific language impairment. Brain Lang 2010;115: $162-81$.

7) Picton TW, Hillyard SA. Human auditory evoked potentials. II: effects of attention. Electroencephalogr Clin Neurophysiol 1974;36: 191-200.

8) Squires NK, Squires KC, Hillyard SA. Two varieties of long-latency positive waves evoked by unpredictable auditory stimuli in man. Electroencephalogr Clin Neurophysiol 1975;38:387-401.

9) Fein G, Turetsky B. P300 latency variability in normal elderly: effects of paradigm and measurement technique. Electroencephalogr Clin Neurophysiol 1989;72:384-94.

10) Polich J. Frequency, intensity, and duration as determinants of $P 300$ from auditory stimuli. J Clin Neurophysiol 1989;6:277-86.

11) Sugg MJ, Polich J. P300 from auditory stimuli: intensity and frequency effects. Biol Psychol 1995;41:255-69.

12) Neuhoff JG. Perceptual bias for rising tones. Nature 1998;395:123-4.

13) Ganapathy MK, Narne VK, Kalaiah MK, Manjula P. Effect of pretransition stimulus duration on acoustic change complex. Int J Audiol 2013;52:350-9.

14) Jasper HH. The ten-twenty electrode system of the International Federation. Electroencephalogr Clin Neurophysiol 1958;10:371-5.

15) Delorme A, Makeig S. EEGLAB: an open source toolbox for analysis of single-trial EEG dynamics including independent component analysis. J Neurosci Methods 2004;134:9-21.

16) Ulanovsky N, Las L, Nelken I. Processing of low-probability sounds by cortical neurons. Nat Neurosci 2003;6:391-8.

17) Butler RA. Effect of changes in stimulus frequency and intensity on habituation of the human vertex potential. J Acoust Soc Am 1968; 44:945-50.

18) Jääskeläinen IP, Ahveninen J, Bonmassar G, Dale AM, Ilmoniemi RJ, Levänen S, et al. Human posterior auditory cortex gates novel sounds to consciousness. Proc Natl Acad Sci U S A 2004;101:680914.

19) Nääänen $R$. The role of attention in auditory information processing as revealed by event-related potentials and other brain measures of cognitive function. Behav Brain Sci 1990;13:201-33.

20) Näätänen R, Picton T. The N1 wave of the human electric and magnetic response to sound: a review and an analysis of the component structure. Psychophysiology 1987;24:375-425.

21) Picton TW. The P300 wave of the human event-related potential. J Clin Neurophysiol 1992;9:456-79.

22) Snyder E, Hillyard SA, Galambos R. Similarities and differences among the P3 waves to detected signals in three modalities. Psychophysiology 1980;17:112-22.

23) Martin BA, Boothroyd A. Cortical, auditory, event-related potentials in response to periodic and aperiodic stimuli with the same spectral envelope. Ear Hear 1999;20:33-44.

24) Martin BA, Boothroyd A. Cortical, auditory, evoked potentials in response to changes of spectrum and amplitude. J Acoust Soc Am 2000;107:2155-61.

25) Kutas M, McCarthy G, Donchin E. Augmenting mental chronometry: the P300 as a measure of stimulus evaluation time. Science 1977; 197:792-5.

26) Magliero A, Bashore TR, Coles MG, Donchin E. On the dependence 
of P300 latency on stimulus evaluation processes. Psychophysiology 1984;21:171-86.

27) Duncan CC, Barry RJ, Connolly JF, Fischer C, Michie PT, Näätänen $\mathrm{R}$, et al. Event-related potentials in clinical research: guidelines for eliciting, recording, and quantifying mismatch negativity, P300, and N400. Clin Neurophysiol 2009;120:1883-908.

28) Polich J. Updating P300: an integrative theory of P3a and P3b. Clin Neurophysiol 2007;118:2128-48.

29) Hall DA, Moore DR. Auditory neuroscience: the salience of looming sounds. Curr Biol 2003;13:R91-3.

30) Rosenblum LD, Wuestefeld AP, Anderson KL. Auditory reachability: An affordance approach to the perception of sound source distance. Ecol Psychol 1996;8:1-24.

31) Davis KA, Voigt HF. Evidence of stimulus-dependent correlated activity in the dorsal cochlear nucleus of decerebrate gerbils. J Neu- rophysiol 1997;78:229-47.

32) Dimitrijevic A, Michalewski HJ, Zeng FG, Pratt H, Starr A. Frequency changes in a continuous tone: auditory cortical potentials. Clin Neurophysiol 2008;119:2111-24.

33) Dimitrijevic A, Starr A, Bhatt S, Michalewski HJ, Zeng FG, Pratt H. Auditory cortical N100 in pre- and post-synaptic auditory neuropathy to frequency or intensity changes of continuous tones. Clin Neurophysiol 2011;122:594-604.

34) Harris KC, Mills JH, He NJ, Dubno JR. Age-related differences in sensitivity to small changes in frequency assessed with cortical evoked potentials. Hear Res 2008;243:47-56.

35) He S, Grose JH, Buchman CA. Auditory discrimination: the relationship between psychophysical and electrophysiological measures. Int J Audiol 2012;51:771-82. 